\title{
Metodologia de baixo custo para mapeamento geotécnico aplicado à pavimentação
}

\author{
Antonio Júnior Alves Ribeiro' ${ }^{1}$, Carlos Augusto Uchôa da Silva ${ }^{2}$, Suelly Helena de Araújo Barroso ${ }^{3}$ \\ ${ }^{1}$ Instituto Federal de Educação, Ciência e Tecnologia do Ceará - IFCE, ajar.junior@gmail.com \\ 2Departamento de Engenharia de Transportes, UFC, uchoa@det.ufc.br \\ ${ }^{3}$ Departamento de Engenharia de Transportes, UFC, suelly@det.ufc.br
}

\section{Recebido:}

21 de outubro de 2017

Aceito para publicação:

23 de dezembro de 2017

Publicado:

30 de abril de 2018

Editor de área:

Francisco Thiago Aragão

\section{Palavras-chaves:}

Geotecnia,

Modelagem Neural,

Geoprocessamento.

\section{Keywords:}

Geotechnics,

Neural Modeling,

Geoprocessing.

DOI:10.14295/transportes.v26i2.1491

\begin{abstract}
RESUMO
Este artigo apresenta uma metodologia de baixo custo para previsão e mapeamento dos valores de CBR (California Bearing Ratio) dos solos nas energias de compactação normal (CBR-N) e intermediária (CBR-I), que possa contribuir para o processo da tomada de decisão, quanto ao seu uso para fins de pavimentação. Utilizou-se Geoprocessamento e Redes Neurais Artificiais (RNA) como técnicas de modelagem, bem como variáveis biofísicas e espaciais para explicar o fenômeno modelado. As características pesquisadas (pedologia, geologia, geomorfologia, vegetação, altimetria e posição) se correlacionaram com os valores de CBR dos solos nas duas energias de compactação. Os dados de CBR foram extraídos de projetos e estudos pré-existentes na área escolhida, neste caso, a Região Metropolitana de Fortaleza (RMF). Dessa forma, calibraram-se, validaram-se e testaram-se diversos modelos em RNA até encontrar os dois modelos de melhor ajuste para a geração de estimativas de CBR-N e CBR-I. As características geotécnicas estimadas por esses modelos possibilitaram a elaboração de dois Mapas Geotécnicos Neurais estratificados para previsão dos valores de CBR-N e CBR-I. Os resultados mostram claramente que a técnica de Redes Neurais Artificiais é promissora, tanto para estimar as propriedades mecânicas dos solos quanto para prever sua ocorrência e localização na área estudada.
\end{abstract}

\section{ABSTRACT}

This paper presents a low-cost methodology for forecasting and mapping of CBR values (California Bearing Ratio) of soils in the energies normal compression (CBR-N) and intermediate (CBR-I), which contribute to the decision-making process as to their use for paving purposes. GIS, Artificial Neural Networks (ANN) and modeling techniques as well as biophysical and spatial variables were used as explanatory of the modeled phenomenon. The researched characteristics (pedology, geology, geomorphology, vegetation, hypsometry and position) correlated with CBR values of soils in both energy compaction. CBR data were extracted from pre-existing projects and studies in the study area, in this case, the metropolitan area of Fortaleza (MAF). Thus, they were calibrated, validated and tested in many different ANN to find the two models best fit, for the generation of CBR-N estimates and CBR-I, of the soil MAF from the studied biophysical variables. The geotechnical characteristics estimated by these models enabled the development of two Neural Geotechnical Maps stratified to predict the values, CBR-N and CBR-I. The results show that ANN technique is promising to predict the mechanical properties of soils and can assist in making decisions regarding the use of these in road projects.

\section{INTRODUÇÃO}

O A existência e o mapeamento de informações geotécnicas confiáveis podem ajudar a reduzir custos e aumentar a qualidade na elaboração e execução de projetos viários, sobretudo diante da dificuldade crescente de se encontrar materiais de uso adequados em pavimentação. Geralmente, nesses projetos busca-se maximizar sua qualidade e minimizar os custos com a coleta e caracterização de materiais. Uma forma de atingir esse objetivo seria a existência de mapas e cartas, a partir de ensaios ou previsão, das 
propriedades geotécnicas dos solos (RIBEIRO et al., 2015). Para Almeida et. al. (2008), é recomendável se evitar o retrabalho na busca e caracterização de materiais, bem como a passagem por acidentes geotécnicos e geológicos de forma a minimizar os custos e maximizar a qualidade da elaboração e execução de um projeto rodoviário.

Estudos quantitativos em solos têm sido desenvolvidos na área da ciência do solo denominada Pedometria e pode ser definida como o desenvolvimento de modelos numéricos ou estatísticos das relações entre variáveis ambientais e o solo, os quais são então aplicados a um banco de dados geográfico para criar um mapa preditivo de ocorrência de solos (SCULL et al., 2003).

Ribeiro et al. (2016) argumentam que, em projetos de pavimentos, é essencial se conhecer o comportamento dos solos quando submetidos ao carregamento do tráfego local, sendo o CBR (California Bearing Ratio) e o MR (Módulo de Resiliência) os parâmetros mais importantes a serem determinados quando o dimensionamento é empírico ou mecanístico-empírico, respectivamente.

Guilherme et. al. (2016) acrescentam que, atualmente, os órgãos rodoviários brasileiros possuem uma grande quantidade de informações resultantes dos estudos geotécnicos de obras rodoviárias já executadas ou em fase de projetos, sendo que tais dados ficam, geralmente, armazenados em relatórios internos dos órgãos rodoviários. Considera-se que essas informações são preciosas e que se fossem mais bem organizadas poderiam compor um banco de dados geotécnico que retratasse a realidade dos tipos de materiais ocorrentes em uma dada região brasileira, podendo assim ser utilizado em modelagens e mapeamentos.

Observa-se que nesses estudos apenas encontram-se informações referentes à classificação da American Association of State Highway and Transportation Officials (AASHTO) e CBR dos solos, tornando possível realizar mapeamentos preditivos, sem necessidade de ensaios de laboratório complementares, apenas desses dois parâmetros.

A existência de mapeamentos preditivos ou de reconhecimento com propriedades de interesse na pavimentação poderia maximizar a qualidade dos anteprojetos rodoviários, pois a carência desses mapeamentos dificulta o conhecimento prévio dos materiais; fato este que geralmente resulta em maior consumo dos recursos naturais, maior tempo de execução e consequentemente elevação dos custos financeiro e ambiental dos projetos rodoviários.

A partir dessas constatações, este artigo objetiva desenvolver mapeamento geotécnico para fins de pavimentação a partir de estimativas de CBR de solos nas energias de compactação normal (CBR-N) e intermediária (CBR-I) para a Região Metropolitana de Fortaleza (RMF), usando para isso, dados préexistentes em projetos rodoviários, Geoprocessamento e Redes Neurais Artificiais (RNA).

\subsection{Formação e propriedades mecânicas dos solos em pavimentação}

A visão mais comum do solo, inicialmente proposta por Dokuchaev no final do século 19, é fundamentada a partir de uma perspectiva pedológica onde o solo é um corpo natural evolutivo que pode ser subdividido em subcompartimentos e que se formou sob a influência de cinco fatores de formação: clima, organismos, materiais de origem, relevo e tempo (BOCKHEIM, et al. 2005).

Lagacherie e McBratney (2007) afirmam que a predição e o mapeamento digital de solos consistem na criação e população de sistemas de informações geográficas de solos utilizando modelos matemáticos para prever as variações espaciais e temporais de classes de solo e suas propriedades.

O primeiro modelo de previsão de classes de solos foi desenvolvido por Jenny na década de 1940 (Equação 1) a partir de variáveis ambientais (MCBRATNEY et al., 2003). Uma nova abordagem para a Equação 1 foi proposta por Hartemink e McBratney (2008), segundo os pesquisadores as classes pedológicas de solo podem ser preditas utilizando-se a Equação 2.

$$
S=(f(c l, o, r, p, t \ldots))
$$

onde $\mathrm{S}$ : $\quad$ solo $\mathrm{cl}=$ clima, $\mathrm{o}=$ organismos, $\mathrm{r}=$ relevo, $\mathrm{p}=$ material de origem e $\mathrm{t}=$ tempo 


$$
S c=(f(s, c, o, r, p, a, n))
$$

onde Sc: classe do solo, $\mathrm{s}=$ solo do mapa existente, $\mathrm{c}=$ clima, $\mathrm{o}=$ organismos, $\mathrm{r}=$ relevo, $\mathrm{p}=$ material de origem, $\mathrm{a}=$ tempo, $\mathrm{n}=$ coordenadas geográficas.

Os processos de formação dos solos incluem todos os fatores condicionantes das propriedades dos solos formados. Esses fatores podem variar, fazendo com que os solos apresentem características e propriedades que se diferenciam uns dos outros, inclusive suas propriedades mecânicas.

A Mecânica dos Solos estuda a aplicação dos solos em engenharia, incluindo seu uso em pavimentação. Na pavimentação, considera-se solo todo material inconsolidado ou parcialmente consolidado, inorgânico ou não, que possa ser escavado sem o emprego de técnicas especiais, como por exemplo, explosivos. Para se praticar a pavimentação, é necessário conhecer as propriedades físicas e químicas dos solos, pois são com os solos e sobre os solos que são construídos os pavimentos (DNIT, 2006).

Para o projeto das estruturas dos pavimentos no Brasil, utilizam-se principalmente dois parâmetros de caracterização mecânica: (1) CBR, para o dimensionamento empírico convencional do DNIT (SOUZA, 1979) e (2) o Módulo de Resiliência (MR) usado para análise e/ou dimensionamento mecanístico-empírico de pavimentos.

Pode-se afirmar que o Módulo de Resiliência (MR) é uma propriedade mecânica do solo e matematicamente pode ser definido como a razão entre a tensão desvio $\left(\sigma_{\mathrm{d}}\right)$ aplicada repetidamente e a deformação específica resiliente correspondente $\left(\varepsilon_{\mathrm{r}}\right)$ (ver Equação 3$)$.

$$
\operatorname{MR}=\sigma_{\mathrm{d}} / \varepsilon_{\mathrm{r}}
$$

Onde: MR = Módulo de Resiliência; $\sigma_{\mathrm{d}}=\sigma_{1}-\sigma_{3}=$ tensão desvio; $\sigma_{1}=$ tensão axial cíclica; $\sigma_{3}=$ tensão de confinamento; $\varepsilon_{\mathrm{r}}=$ deformação recuperável ou resiliente.

0 termo resiliente refere-se a quando um material é solicitado por cargas repetidas, no caso do tráfego, aplicadas em frações de segundos. Essas cargas provocam deslocamentos verticais transientes nos materiais. Uma vez cessada a ação das cargas, parte desse deslocamento se torna permanente, não recuperável, e parte é resiliente, recuperável.

0 ensaio de MR tem basicamente duas fases, a primeira é chamada fase de condicionamento e objetiva reduzir a influência das grandes deformações plásticas e reduzir o efeito da história de tensões no valor do Módulo de Resiliência. É na verdade uma sequência de carregamentos dinâmicos (maiores detalhes consultar em DNIT 134/2016 - ME) que permite dotar o material de uma condição como de "pré-adensamento". A obtenção dos valores de MR é feita na segunda fase do ensaio, onde para cada par de tensões $\sigma_{\mathrm{d}}$ (tensão desvio) e $\sigma_{3}$ (tensão confinante) aplicado é feita a medição da deformação resiliente (maiores detalhes consultar em DNIT 134/2016 - ME). 0 Módulo de Resiliência é então calculado, obtendo-se, por regressão linear, os valores das constantes $\left(\mathrm{K}_{\mathrm{i}}\right)$ dos modelos de comportamento resiliente adotados.

O método de dimensionamento de pavimentos asfálticos que utiliza o MR como parâmetro de dimensionamento no Brasil já está pronto e irá se chamar Método de Dimensionamento Nacional (MeDiNa), este deverá ser disponibilizado pelo DNIT no $1^{\mathrm{O}}$ semestre de 2018. 0 novo método foi concebido por meio do projeto Rede Temática de Asfalto com financiamento da Petrobras, envolvendo as mais importantes universidades brasileiras e o DNIT. A versão do método que será publicada em breve foi embasada, principalmente, nos trabalhos de Franco (2007) e Fritzen (2016). Enquanto o novo método não é implementado, o método oficial de dimensionamento de pavimentos brasileiro continua sendo o que utiliza o CBR como parâmetro de dimensionamento.

0 ensaio para a determinação do CBR foi concebido no final da década dos anos 20 para avaliar o potencial de ruptura do subleito, uma vez que esse era o defeito mais frequentemente observado nas rodovias do estado da Califórnia naquele período. 0 ensaio foi idealizado, portanto, para avaliar a resistência do material frente a deslocamentos significativos, sendo obtida por meio de ensaio penetrométrico em laboratório.

A resistência ou capacidade de suporte CBR foi correlacionada empiricamente com o desempenho das estruturas levando a um método de dimensionamento de pavimentos que fixa espessuras mínimas 
da estrutura dependendo do índice de suporte do subleito, de modo a limitar tensões e protegê-lo da ruptura. Esse método serviu como referencial para o desenvolvimento de outros métodos, como o do Corpo de Engenheiros norte-americanos e, mais tarde, o método brasileiro do DNER, de 1966 e revisto em 1981.

O ensaio de CBR é regido no Brasil pela especificação DNER-ME 049/94, que consiste, de forma sucinta, nas seguintes etapas: compactação do corpo de prova, imersão dos corpos de prova em água para medida de expansão axial e ensaio de penetração.

Não se tem conhecimento da existência de mapas representando o CBR para qualquer região do Brasil e do mundo. Contudo, Ribeiro et al. (2015) desenvolveram mapas de predição da classificação da AASHTO para a RMF a partir de dados geotécnicos pré-existentes. Para possibilitar a confecção de mapas com essa informação se faz necessária adoção de ferramentas e funções de Geoprocessamento.

\subsection{Geoprocessamento}

Segundo Câmara et al. (2004) e Câmara (1996), o termo geoprocessamento denota o ramo do conhecimento que utiliza técnicas matemáticas e computacionais para o tratamento da informação geográfica e que vem influenciando de maneira crescente as áreas de cartografia, análise de recursos naturais, transportes, comunicações, energia e planejamento urbano e regional. As ferramentas computacionais para o Geoprocessamento são chamadas de Sistema de Informação Geográfica (SIG) e permitem realizar análises complexas, ao integrar dados de diversas fontes e ao criar bancos de dados georreferenciados.

Os SIG têm sido utilizados nas mais diversas áreas do conhecimento com diferentes abordagens e com capacidade de contribuir com processos de análise, monitoramento e controle ambiental, utilizando conjuntamente técnicas estatísticas de análises de dados (OH e PRADHAN, 2011). Segundo Bui et al. (2014), o uso dos SIG em modelagem que envolvem o meio ambiente como variável facilita o processo de análise e manuseio dos dados espaciais com eficácia e rapidez de processamento, fato que este que facilita a organização dos dados para o processo de modelagem.

Em um SIG, o banco de dados é integrado aos elementos espaciais de tal forma que armazene as informações do meio físico. Tomando como exemplo a Cartografia Geotécnica, podem-se ter os pontos de sondagens espacializados e a esses pontos agregarem-se uma base de dados com todas as informações geotécnicas obtidas para o referido ponto (RIBEIRO, et al., 2016).

A criação de bases de dados pode ajudar na previsão de variáveis geotécnicas utilizando técnicas como: Redes Neurais Artificiais (RNA) e ferramentas estatísticas.

\subsection{Redes Neurais Artificiais e modelagem de solos}

As Redes Neurais Artificiais (RNA) são técnicas da Inteligência Artificial (IA) que tentam simular o funcionamento do cérebro humano em sistemas computacionais de maneira simplificada. Para isso são usados sistemas paralelos distribuídos compostos por unidades de processamento simples (neurônios) que calculam determinadas funções matemáticas (e não lineares). Essas unidades são dispostas em uma ou mais camadas e interligadas por um grande número de conexões, geralmente unidirecionais (HAYKIN, 2001).

As RNA são constituídas de neurônios artificiais, projetados para simular o comportamento do neurônio biológico, assemelhando-se ao cérebro em dois aspectos principais: o primeiro se refere ao conhecimento que é adquirido pela rede a partir de seu ambiente através de um processo de aprendizagem; já o segundo aspecto leva em consideração a intensidade da conexão entre neurônios, conhecidas como pesos sinápticos, que são utilizadas para armazenar o conhecimento adquirido (HAYKIN, 2001).

O modelo inicial para um neurônio artificial, proposto por Mcculloch e Pitts (1943) foi posteriormente aprimorado por Rosenblatt (1958), que o nomeou de Perceptron. Esse neurônio representa uma aproximação simplificada sob a ótica neurofisiológica, porém conserva várias características de um neu- 
rônio biológico e viabiliza sua implementação computacional. Do ponto de vista matemático, a representação do neurônio k é descrito pelas Equações 4, 5 e 6.

$$
\begin{aligned}
u k & =\sum w_{k i} x_{i} \\
v k & =u_{k}+b_{k} \\
y k & =\varphi(v k)
\end{aligned}
$$

Onde: $\mathrm{x}_{\mathrm{i}}$ são as entradas da rede, $\mathrm{w}_{\mathrm{ki}}$ são os pesos, ou pesos sinápticos, associados a cada entrada, $b_{\mathrm{k}}$ é o termo bias, uk é a combinação linear dos sinais de entrada, $\varphi$ (.) é a função de ativação e yk é à saída do neurônio.

Dentre os tipos de redes neurais utilizados para a modelagem de fenômenos em engenharia, destacam-se as MLP (Multi Layer Perceptrons). A MLP é uma rede neural constituída por três tipos camadas: a camada de entrada, cuja função é a de receber os estímulos externos; uma ou mais camadas intermediárias, também denominadas ocultas, responsáveis pelo aumento da capacidade da rede neural artificial em extrair o comportamento mais complexo do ambiente, no qual a rede está inserida; e a camada de saída, cuja função é a de dar as respostas para os estímulos apresentados à rede neural.

Uma das mais importantes propriedades de uma rede neural é a sua habilidade de aprender a partir dos exemplos que lhe são apresentados e melhorar seu desempenho através de um processo contínuo de treinamento. 0 treinamento de uma rede neural artificial consiste na alteração de todos os pesos sinápticos $\left(w_{\mathrm{ki}}\right)$ e limiares existentes $\left(\mathrm{b}_{\mathrm{k}}\right)$, a partir da experiência conhecida sobre o fenômeno estudado, normalmente disponível em um conjunto de dados do tipo entrada conhecida e saída conhecida.

De modo geral, o desenvolvimento de um modelo de RNA requer a seleção de dados de treinamento, a escolha de uma arquitetura adequada e um exaustivo e cuidadoso processo de treinamento e validação (BORUVKA e PENIZEK, 2007). As RNA bem como outras técnicas de modelagem têm sido utilizadas com sucesso na previsão de características geotécnicas e mapeamento digital de solos.

Zeghal e Khogali (2005) previram com sucesso o MR para materiais granulares utilizando RNA, tendo como dados de entrada: a densidade, o estado de tensões e a umidade do material.

Caten et al. (2009) calibraram modelos de regressões logísticas múltiplas com acertos da ordem de 51\% para a predição de classes de solos do município de São Pedro do Sul - RS. Nesse estudo foram utilizadas variáveis derivadas de um modelo de elevação do terreno para extrair os atributos que serviram de dados de entrada do modelo logístico. Tais atributos foram os seguintes: elevação, distância de declividade com a aproximação de fluxo, curvatura planar do perfil, curvatura, iluminação, logaritmo natural da área de contribuição, índice de umidade topográfica e capacidade de transporte de sedimentos.

Kempen et al. (2009) atualizaram o mapa de solo da província de Drenthe (2.680 $\left.\mathrm{km}^{2}\right)$ na Holanda, sem trabalho de campo adicional através de mapeamento digital de solos utilizando características básicas de solos. Esses autores utilizaram a técnica de regressão logística multinomial para prever a relação entre variáveis básicas do solo e o grupo do solo (pedologia). Uma estrutura para a construção de um modelo de regressão logística foi retirada da literatura e adaptado para a finalidade de mapeamento de solos. 0 processo de construção do modelo foi guiado por conhecimento especializado de pedologia para assegurar que o modelo final de regressão não só fosse estatisticamente confiável, mas também pedologicamente correto. Os acertos desse modelo foram, aproximadamente, de 67\%.

Debella-Gilo e Etzelmüller (2009) utilizaram a técnica de regressão logística multinomial integrada com Sistemas de Informações Geográficas para modelar a distribuição espacial das 13 classes de solos no condado Vestfold no sudeste da Noruega. Em primeiro lugar, as relações entre os grupos de solos e os atributos do terreno foram modelados por meio de regressão logística multinomial. Em seguida, a probabilidade de que um dado tipo de solo estar presente em um dado pixel foi determinada a partir do modelo logit no SIG ArcGIS para mapear a distribuição espacial contínua cada grupo de solos. Os atributos do terreno mais significativos e utilizados para a modelagem foram: elevação, comprimento, fluxo de 
água, tempo diário de radiação solar direta, declividade, aspecto topográfico e índice de umidade. A previsão apresentou valores de probabilidade médios para cada grupo de solo em áreas realmente abrangido por cada grupo de solo em comparação com outras áreas, indicando a confiabilidade da predição.

Gunaydin et al. (2010) apresentaram a aplicação de diferentes métodos simples de múltipla análise e RNA para a previsão da Resistência à Compressão Simples (RCS) a partir de propriedades básicas do solo. A análise de regressão e redes neurais artificiais indicou que existem correlações aceitáveis entre as propriedades do solo e a RCS. Além disso, a técnica de redes neurais artificiais mostrou maior desempenho quando comparada aos tradicionais modelos estatísticos com a mesma finalidade.

Taskiran (2010) afirmou que a maioria dos modelos de previsão de valores de CBR existentes são essencialmente correlações estatísticas e que muitos desses modelos, geralmente, produzem valores de CBR insatisfatórios. Na tentativa de criar modelos de previsão de CBR mais realistas, o autor aplicou técnicas de RNAs e Algoritmos Genéticos para a predição de CBR de solos finos da Anatólia, região sudeste da Turquia. Os resultados mostraram que ambas as técnicas utilizadas são capazes de aprender e inferir a relação entre CBR e propriedades básicas dos solos, tais como: massa específica seca máxima, índice de plasticidade, umidade ótima, teores de (areia, argila e silte), limite de liquidez e conteúdo de cascalho.

Johari et al. (2011) juntaram redes neurais e algoritmos genéticos para a modelagem do comportamento mecânico de solos não saturados por meio de ensaios triaxiais. Na abordagem proposta, um algoritmo genético foi usado para otimizar os pesos da rede neural. Os dados de entrada utilizados no modelo foram: densidade seca, deformação axial, grau de saturação, tensão desvio e tensão média.

Yildirim e Gunaydin (2011) utilizaram com sucesso RNA para previsão dos valores de CBR das camadas dos pavimentos de vias públicas de diversas cidades de regiões diferentes da Turquia. Os dados de entrada foram: análise granulométrica, limites de Atterberg, massa específica seca máxima e umidade ótima.

\section{MATERIAIS E MÉTODOS}

\subsection{Dados utilizados para elaboração do trabalho}

Para realizar o mapeamento geotécnico de CBR-N e CBR-I da Região Metropolitana de Fortaleza (RMF), foram utilizados dados geotécnicos secundários e informações de variáveis biofísicas em formato de polígonos georreferenciados. Os dados de CBR-N e CBR-I foram extraídos dos relatórios de projetos rodoviários disponibilizados pelo DNIT (Departamento Nacional de Infraestrutura de Transportes) e dados constantes em Barroso (2002).

Já as variáveis biofísicas (Geologia, Pedologia, Geomorfologia, Vegetação, Coordenada Este, Coordenada Norte, Altimetria) foram adquiridas junto aos órgãos governamentais: CPRM (Serviço Geológico do Brasil), Embrapa (Empresa Brasileira de Pesquisas Agropecuárias) e IPECE (Instituto de Pesquisas Econômicas do Ceará).

\subsection{Geoprocessamento dos Dados}

Nessa etapa, os pontos relativos à coleta de dados geotécnicos nos órgãos, empresas e trabalhos acadêmicos (sondagens do subleito, sondagens de empréstimos e sondagens de jazidas), foram adquiridos em formato analógico e não georreferenciados. Sendo assim, os pontos foram georreferenciados segundo a metodologia desenvolvida por Ribeiro et al., (2016). Na sequência, os pontos geotécnicos foram cruzados com informações biofísicas de sua localização espacial, formando uma única base de dados através da Álgebra de Mapas.

Em seguida, foram selecionados os mapas relativos à Pedologia, Geologia, Vegetação, Geomorfologia, Altimetria, Coordenadas planimétricas (Este, Norte). Esses mapas foram cruzados com a finalidade de associar espacialmente cada ponto com CBR às variáveis biofísicas.

Para realizar essa operação, utilizou-se a função Spatial Join do ArcGIS que possibilitou o cruzamento 
dos dados e formou uma única camada vetorial, fruto dessas operações e que contém todas as informações necessárias para a modelagem. Posteriormente, os arquivos vetoriais, em formato shapefile, foram exportados para o formato .xlsx a fim de serem pré-processados no Excel.

\subsection{Pré-processamento dos Dados}

Nesta etapa, os dados georreferenciados foram extraídos do SIG em formato tabular e foram submetidos a um pré-processamento com a finalidade de se adequarem às restrições impostas pela modelagem neural. Tal processamento consistiu em transformação dos valores de CBR em variáveis Dummy (valores entre 0 e 1). A Tabela 1 apresenta um exemplo do pré-processamento com variáveis Dummy (Dummyzação).

Tabela 1 - Exemplo de pré-processamento realizado

\begin{tabular}{ll}
\hline Números & Dummy \\
\hline$(1,2,3)$ & $(001,010,100)$ \\
$(1,2,3,4)$ & $(0001,0010,0100,1000)$ \\
$(1,2,3,4,5)$ & $(00001,00010,00100,01000,10000)$ \\
\hline
\end{tabular}

\subsection{Modelagem Neural dos CBR-N e CBR-I}

0 processamento dos dados em uma RNA consiste em treinar, validar e testar o modelo adotado. Para isso, utilizou-se um o Neural Network Tool (NNTOOL), que possibilita a construção de diferentes topologias, com variações de algoritmos e parâmetros de treinamento de RNA no aplicativo MATLAB. Assim, foi elaborada uma árvore de testes que nada mais é que desenvolver uma série de testes no NNTOOL buscando encontrar uma arquitetura mais adequada para o problema em questão. Essa ferramenta tem sido empregada em diversos trabalhos que utilizaram modelagem através de RNA.

Os dados utilizados para realizar o treinamento dos modelos, desenvolvidos aqui, foram divididos em três conjuntos cada, sendo $60 \%$ utilizados para treinamento, $20 \%$ para validação e $20 \%$ para teste. Esses conjuntos de dados foram selecionados randomicamente sem repetição. Os dados de entrada das redes foram as variáveis biofísicas: Pedologia, Geologia, Vegetação e Geomorfologia, Altimetria e Coordenadas Este e Norte e o dado de saída das redes são as características geotécnicas (CBR-N e CBR-I).

Após a definição dos conjuntos de dados, foi iniciado o treinamento das RNA com a finalidade de encontrar a(s) melhor(es) topologia(s) que se ajustasse(m) aos fenômenos estudados. Para isto, foram testados diversos algoritmos, bem como realizou-se a variação de seus parâmetros (número de camadas intermediárias, quantidade de neurônios em cada camada, taxa de aprendizagem, termo momentum, número de épocas de treinamento e outros).

0 algoritmo selecionado para iniciar os testes foi o Levenberg-Marquardt, com termo de momento. Esse algoritmo é uma das formas modificadas do algoritmo backpropagation, o qual utiliza o método de Newton, para aproximar o mínimo da função de erro (HAYKIN, 2001). A escolha inicial desse algoritmo deu-se em função das recomendações contidas em Beale et al. (2010), que sugerem seu uso por ser um algoritmo de treinamento rápido quando se tem um conjunto de treinamento de tamanho não muito grande e por apresentar bons resultados de generalização para a maioria dos casos.

\section{RESULTADOS E DISCUSSÃO}

A ideia principal desta investigação é o desenvolvimento de um método para estimação e localização das características geotécnicas de interesse à pavimentação (CBR-N e CBR-I) dos solos da RMF de forma indireta, eficaz, rápida e de baixo custo.

Do total de pontos, verificou-se que 547 possuem o valor do CBR-N e são oriundos de investigações do subleito, bem como 389 pontos têm o valor do CBR-I e são oriundos de investigações de jazidas e empréstimos. As informações referentes aos pontos geotécnicos adquiridos da região em estudo podem 
ser visualizadas nas Figuras 1 e 2, as quais são mapas que ilustram tais dados. A partir desses mapas foi possível extrair informações de distribuição dos dados, bem como fazer um cruzamento espacial desses pontos com as bases cartográficas oriundas das variáveis biofísicas utilizadas aqui como variáveis explicativas dos modelos propostos.

Pode-se verificar na Figura 3 que os valores de CBR-N do subleito que predominam estão entre $0 \%$ e $30 \%$, para os valores de CBR-N entre 30\% e 60\% encontram-se em quantidades bem inferiores. Já na Figura 4 observa-se que dentre os valores de CBR-I, de jazidas e empréstimos, predominam os valores entre $6 \%$ e $45 \%$.

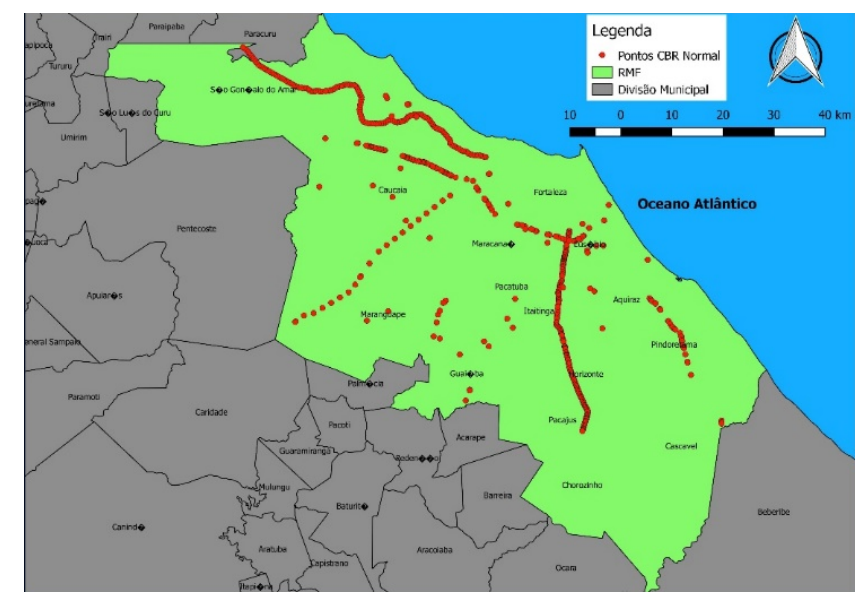

Figura 1. Distribuição Espacial dos 547 Pontos com Valores de CBR-N

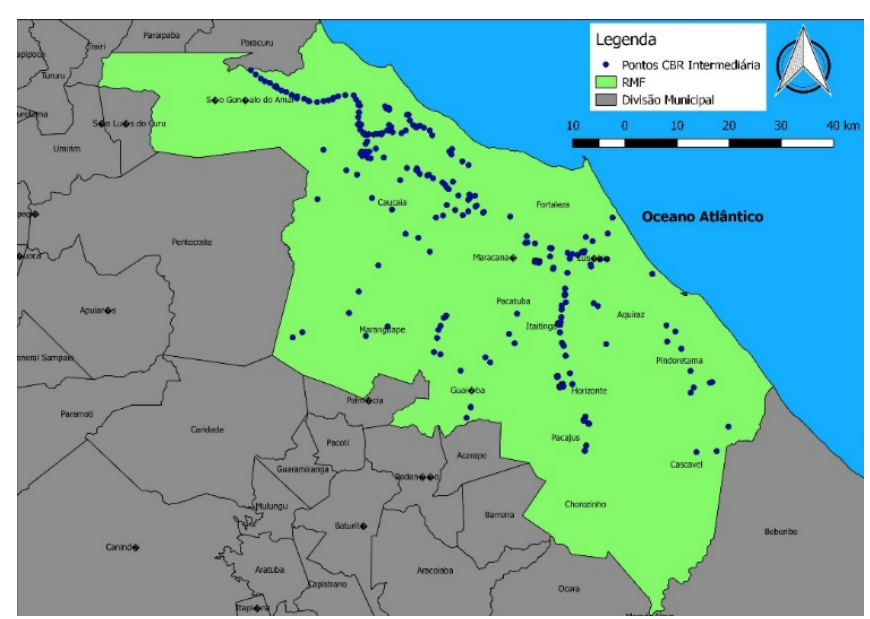

Figura 2. Distribuição Espacial dos 389 Pontos com CBR-I

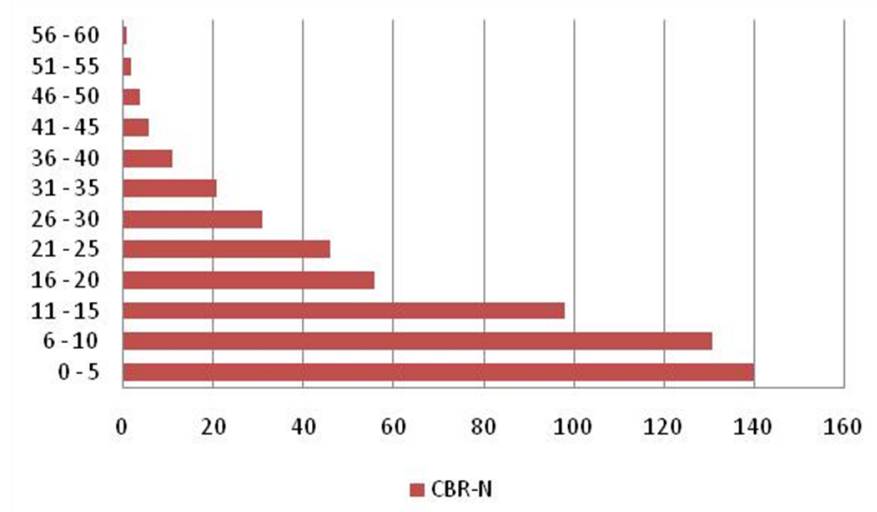

Figura 3. Estratificação dos Pontos com CBR-N. 


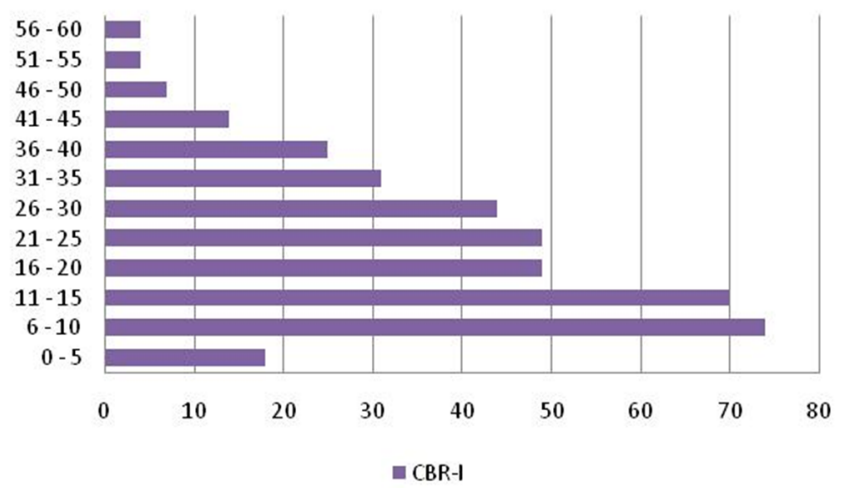

Figura 4. Estratificação dos Pontos com CBR-I

De posse dos mapas e gráficos elaborados (Figuras 1 a 4), foi possível realizar algumas análises básicas acerca das amostras dos dados geotécnicos utilizados para a modelagem dos valores de CBR. Podese perceber que os pontos nos mapas têm boa representatividade espacial (boa distribuição na área da RMF) do ponto de vista qualitativo e que os dados de CBR-I têm uma melhor distribuição espacial quando comparado aos dados de CBR-N.

Como esses dados são provenientes de estudos geotécnicos rodoviários, cada ponto também possui informações de compactação, caracterização básica (Granulometria e Limites de Consistência) e classificação da AASHTO. Dessa forma, foram elaborados gráficos (Figuras 5 e 6) com os percentuais dos pontos em relação à classificação da AASHTO para CBR-N e CBR-I, respectivamente. Ainda foram elaborados mais dois gráficos (Figuras 7 e 8) os quais apresentam a variação dos valores máximos, médios e mínimos dos CBR-N e CBR-I em função da Classe AASHTO dos solos. Isso foi feito com intuito de mostrar os tipos de solos ocorrentes na região e também demonstrar que o banco de dados representa as principais classes de solos que ocorrem na região em estudo.

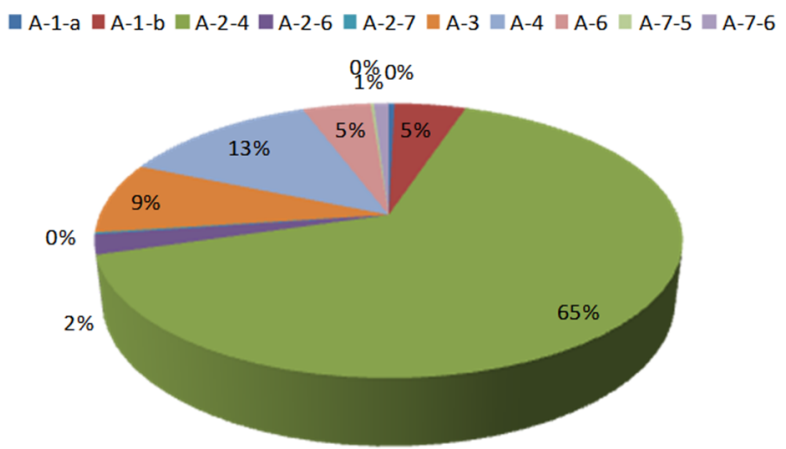

Figura 5. Percentuais de Solos por classe da AASHTO para CBR-N

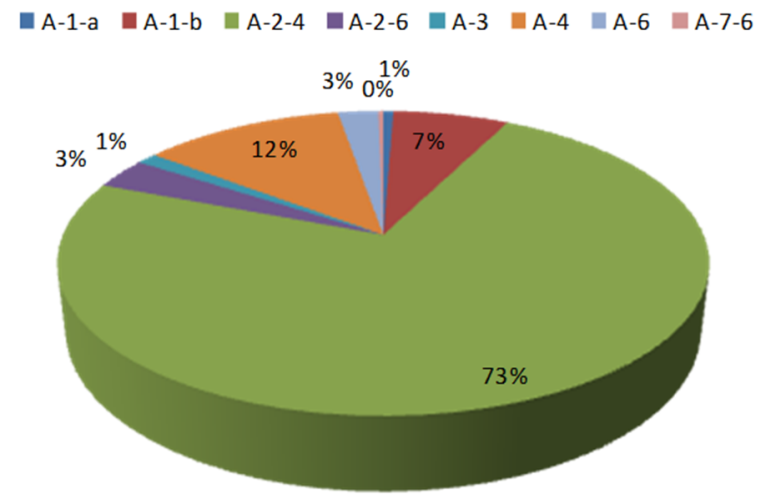

Figura 6. Percentuais de Solos por classe da AASHTO para CBR-I 
Observando os gráficos representados nas Figuras 5 e 6, conclui-se que o banco de dados é composto por 10 classes AASHTO para CBR-N e 8 classes para o CBR-I. A classe AASTHO predominante nos dois bancos de dados é A-2-4, em seguida aparecem as classes A-3, A-4 e A-1-b com frequência superior as demais. Esses tipos de solos são bastante comuns na RMF, que tem como principal formação geológica o Barreiras.

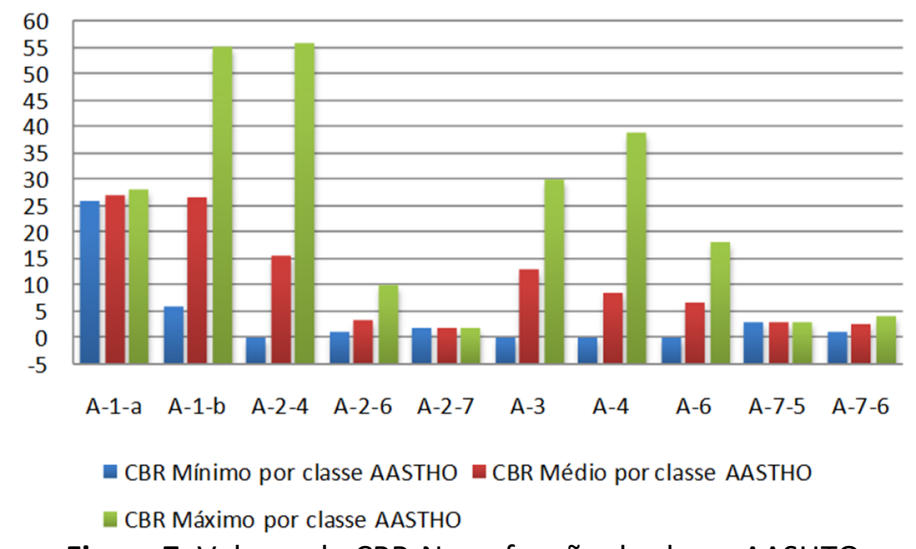

Figura 7. Valores de CBR-N em função da classe AASHTO

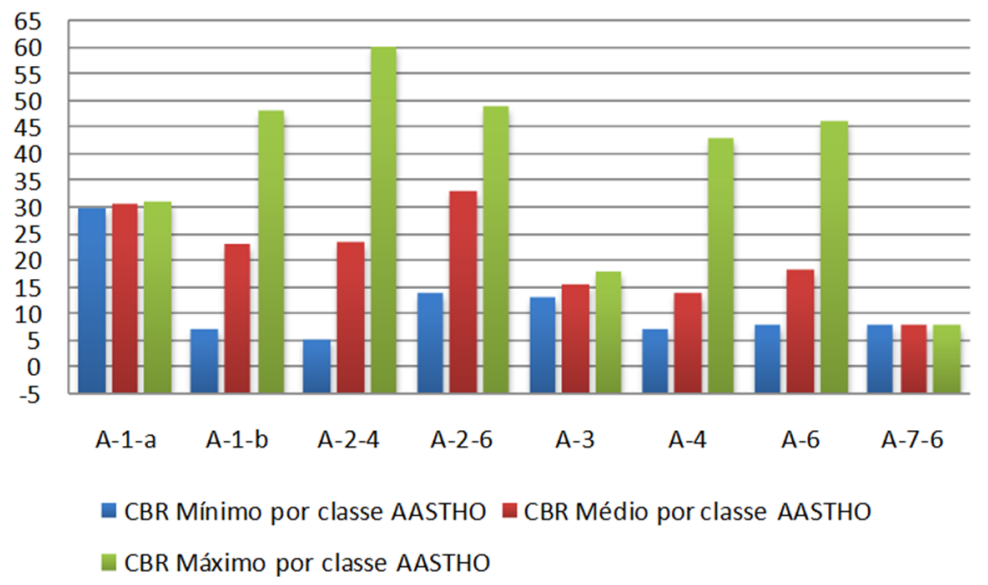

Figura 8. Valores de CBR-I em função da classe AASHTO

A partir dos gráficos de CBR em função da classificação da AASHTO, percebe-se que os valores máximos de CBR ocorrem em solos do tipo A-2-4, contudo esta classe também apresenta valores nulos de CBR. Nota-se que as classes que apresentam os menores valores de máximo são as classes que representam os solos finos, comportamento este já esperado pela própria classificação da AASHTO.

\subsection{Desempenho da Modelagem}

Para realizar a modelagem neural dos CBR-N e CBR-I, os dados foram organizados de forma que as variáveis biofísicas fossem usadas como dados de entrada das RNA (Pedologia, Geologia, Vegetação e Geomorfologia, Altimetria, Coordenada Este, Coordenada Norte) para que correspondessem aos dados de saída (CBR-N e CBR-I) do mesmo ponto geográfico.

Para se modelar os dois tipos de valores de CBR, foram testados diversos algoritmos do tipo backpropagation feed-forward. Verificou-se que o algoritmo TRAINLM (Levenberg-Marquardt) foi o que produziu os melhores resultados.

Para medir-se o desempenho das topologias testadas, adotou-se o MSE (Mean of Squared Error) ou (Quadrado Médio dos Erros) - medida de desempenho encontrada em Ribeiro et al. (2015), sendo a mesma definida pela Equação (7). 


$$
M S E=\frac{S S E}{n-p}
$$

onde SSE: diferenças quadráticas entre os valores de saída da RNA;

n: $\quad$ número de exemplos do conjunto de treinamento (quantidade de padrões);

p: $\quad$ número de parâmetros a serem estimados (quantidade de pesos da rede).

A Figura 9 ilustra o desempenho da modelagem para o conjunto de testes dos dois modelos. As topologias ótimas para a predição do CBR-N e CBR-I com MSE de 0,091 e 0,093, respectivamente, foi a mesma, tendo a seguinte arquitetura:

- Algoritmo TRAINLM (Levenberg-Marquardt);

- Uma camada de entrada com 7 neurônios representados por Pedologia, Geologia, Vegetação, Geomorfologia, Altimetria e Coordenadas Este e Norte;

- Uma camada intermediária (hidden layer) com 100 neurônios;

- Uma camada de saída com 12 neurônios para CBR-N e CBR-I;

- Uso da função de ativação identidade na camada de entrada, função de ativação tangente sigmoidal (tansig) com intervalo de ativação [-1; 1] para as camadas intermediárias e função identidade na camada de saída.

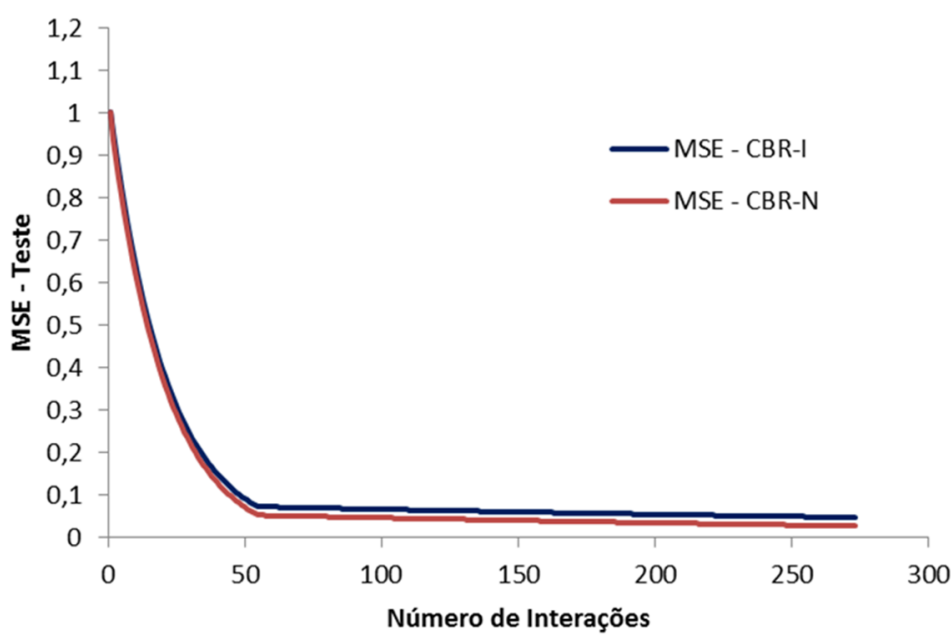

Figura 9. Desempenho do MSE para o conjunto de testes

Os índices de acertos dos modelos foram medidos pelo conjunto de teste, pois destes dados à rede neural não conhecia as saídas, sendo as saídas da RNA comparadas aos dados reais apresentados à rede apenas após os testes. Foi através destes que se mediu o desempenho dos modelos calibrados quando da generalização realizada para toda a RMF. A quantidade de dados disponíveis para testes foi representada por $20 \%$ do total de pontos levantados (547 para CBR-N e 389 para CBR-I). Logo, a quantidade de pontos para teste influenciou diretamente nos resultados do MSE e nos acertos deste conjunto na modelagem.

\subsection{Generalização dos Resultados para a RMF}

A partir dos resultados da previsão neural dos dois diferentes tipos de CBR, foi possível realizar extrapolações para todo o território da RMF. Este resultado foi denominado de Mapeamento Geotécnico Neural da RMF.

A partir dos resultados obtidos pelas modelagens das RNAs, foram gerados dois mapas temáticos, um mapa referente às estimativas de valores de CBR-N (Figura 10) e outro mapa de CBR-I (Figura 11), que poderão ajudar aos tomadores de decisão acerca da ocorrência dos diferentes tipos de solos na RMF e 
com potencial para uso na pavimentação. Adicionalmente, foram mapeadas as Unidades de Conservação, as Terras Indígenas, as Zonas Costeiras (Dunas e Estuários), as Zonas Urbanas, as APA e as APP, destacando-se que estas não devem ser exploradas para retirada de materiais para uso na engenharia.

Os valores de CBR nas energias de compactação normal e intermediária foram generalizados para toda a RMF com a mesma precisão do modelo gerado. Tais valores de CBR, para ambas as energias, foram modelados por faixas de intervalo igual a 5 (cinco) unidades. As Figuras 10 e 11 são os mapas que ilustram a generalização do modelo na RMF para as duas energias de compactação.

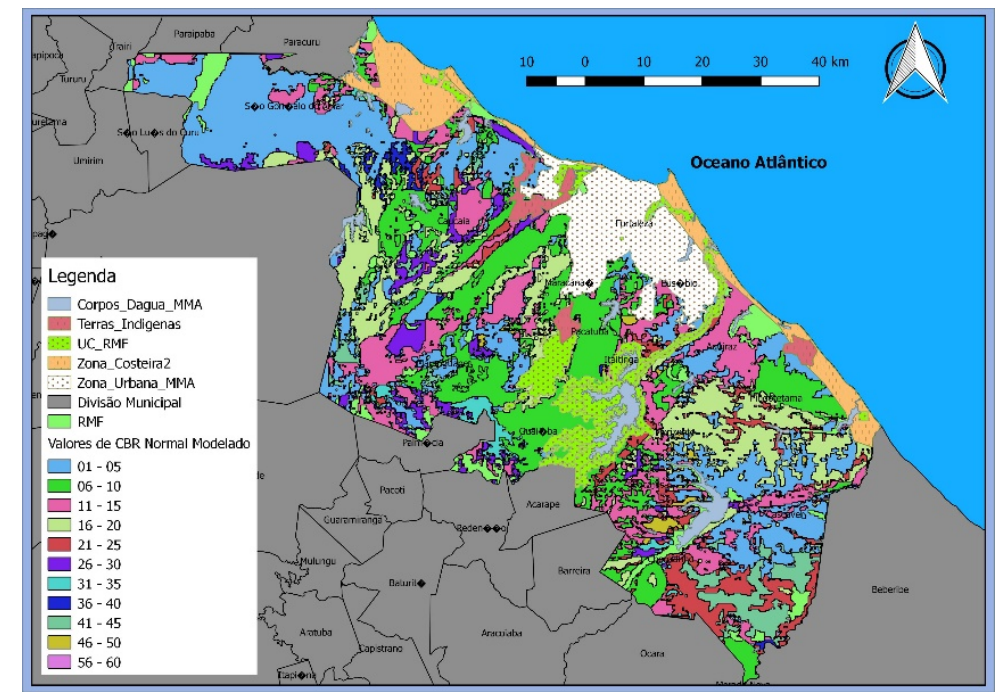

Figura 10. Mapa de CBR-N para RMF

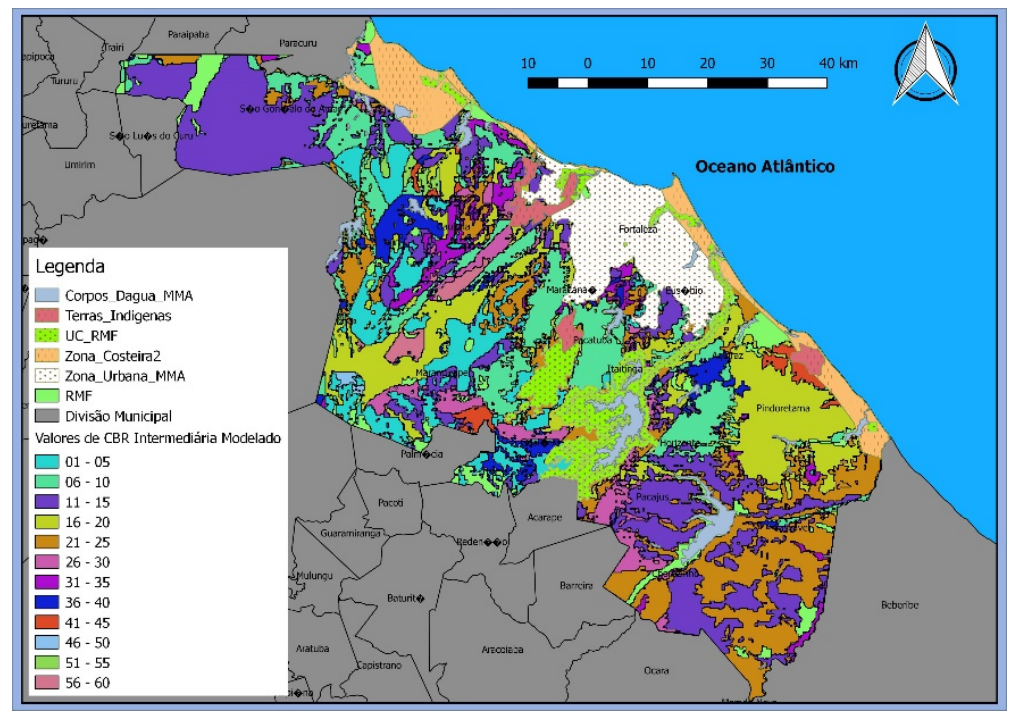

Figura 11. Mapa de CBR-I para a RMF

Analisando os mapas das Figuras 10 e 11, verifica-se que, aproximadamente, 93\% dos solos da RMF têm valores de CBR-N entre 1 e 30\%. Já para o CBR-I, em torno de $90 \%$ dos solos ocorrentes também apresentam valores entre 1 e 30\%. É possível afirmar que $70 \%$ dos solos presentes na área da RMF possuem os valores de CBR-N entre 0 e $15 \%$ e que $50 \%$ possuem CBR-I entre 1 e $15 \%$.

Com intuito de verificar o uso dos materiais modelados de maneira mais simples, procurou-se simplificar os mapas das Figuras 10 e 11 em outros dois mapas (Figuras 12 e 13), os quais ilustram o possível uso dos materiais em estruturas de pavimentos, de acordo com manual de pavimentação do DNIT (2006), o qual classifica os materiais quanto ao potencial uso em camadas de pavimentos: Subleito (CBR 
$\geq 2 \%$ ), Reforço de Subleito (CBR superior ao do Subleito), Sub-Base (CBR $\geq 20 \%$ ) e Base para (RBV) Rodovias de baixo Volume de Tráfego (CBR $\geq 60 \%$ ) e Base (CBR $\geq 80 \%$ ).

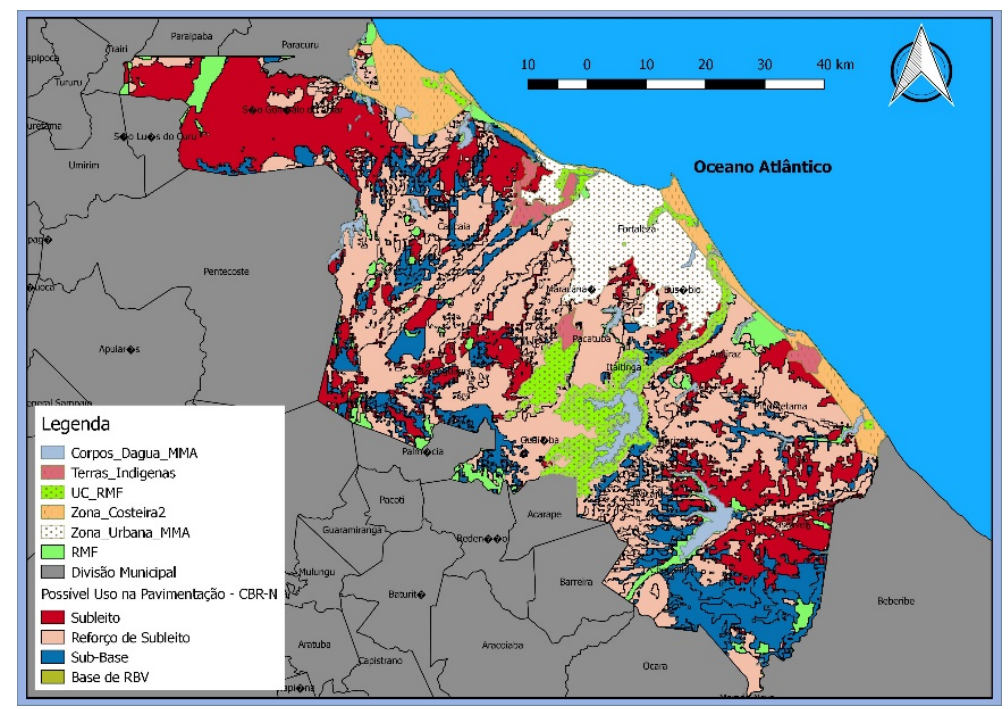

Figura 12. Mapa de Possível Uso para o CBR-N

Para o mapa de uso CBR-N, identificou-se que aproximadamente $50 \%$ dos solos ocorrentes na RMF podem ser empregados sem estabilização granulométrica ou química em camadas de reforço de subleito de pavimentos. Também se identificou que aproximadamente $20 \%$ dos solos podem ser empregados em camadas de sub-base, ainda aproximadamente $25 \%$ podem ser empregado apenas como subleito e em torno de $5 \%$ pode ser empregado como base para RBV.

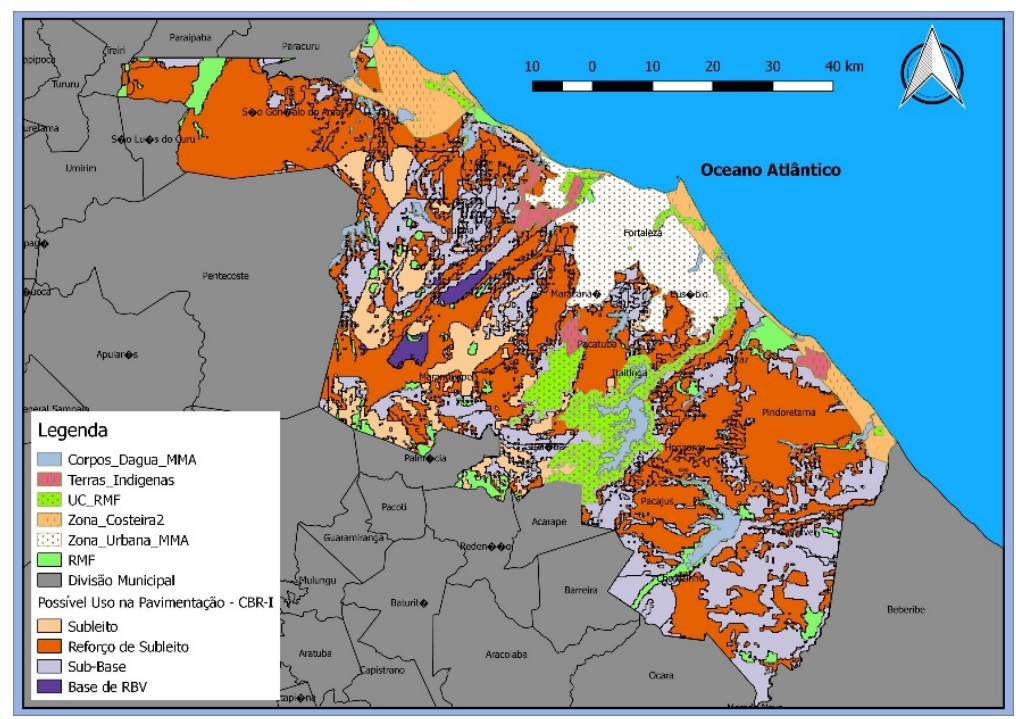

Figura 13. Mapa de Possível Uso para o CBR-I

Já para o mapa de uso CBR-I, 65\% dos solos que cobrem a RMF podem ser empregados sem estabilização em camadas de reforço de subleito de pavimentos. Pode-se observar que $25 \%$ dos materiais ocorrentes na RMF podem compor camadas de sub-base, também verifica-se que $5 \%$ podem compor camadas de base de RBV e 5\% tem comportamento mecânico apenas para compor subleito, não podendo ser utilizado em camadas nobres de pavimentos.

Após a criação dos mapas, foram coletadas e ensaiadas 20 amostras de cada solo, distribuídas na região de estudo, com intuito de verificar a exatidão dos modelos propostos e realizados uma série de 
ensaios de caracterização básica (granulometria, limites de consistência), compactação e CBR pela especificação DNER-ME 049/94.

Essas amostras foram selecionadas com base na Classificação da AASHTO dos solos utilizado na modelagem, onde se buscou coletar solos de cada classe as quais representasse os modelos, tomando como base os percentuais citados nas Figuras 5 e 6. Para auxiliar a coleta com base na classificação da AASHTO, utilizou-se o mapa de previsão de classes AASTHO publicado em Ribeiro et. al. (2015) e priorizou-se a ocorrência de solos próximos a rodovias para facilitar a logística de coleta e a economia de recursos. A Tabela 2 apresenta a quantidade de pontos por classe AASHTO dos solos coletados e ensaiados.

Após a realização dos ensaios foi possível comparar os resultados obtidos em laboratório com os resultados modelados utilizando o modelo calibrado pela ferramenta de RNA do MatLAB. Os resultados podem ser vistos nas Figuras 14 e 15, as quais apresentam as curvas de dispersão entre os valores modelados e ensaiados e seus coeficientes de correlação para os modelos CBR-N e CBR-I, respectivamente.

Tabela 2: Resumo dos solos coletados e ensaiados por classe AASHTO

\begin{tabular}{lll}
\hline Classe & Quantidade de amostras & Percentual (\%) \\
\hline A-1-b & 2 & 10,00 \\
A-2-4 & 12 & 60,00 \\
A-3 & 2 & 10,00 \\
A-4 & 3 & 15,00 \\
A-6 & 1 & 5,00 \\
\hline
\end{tabular}

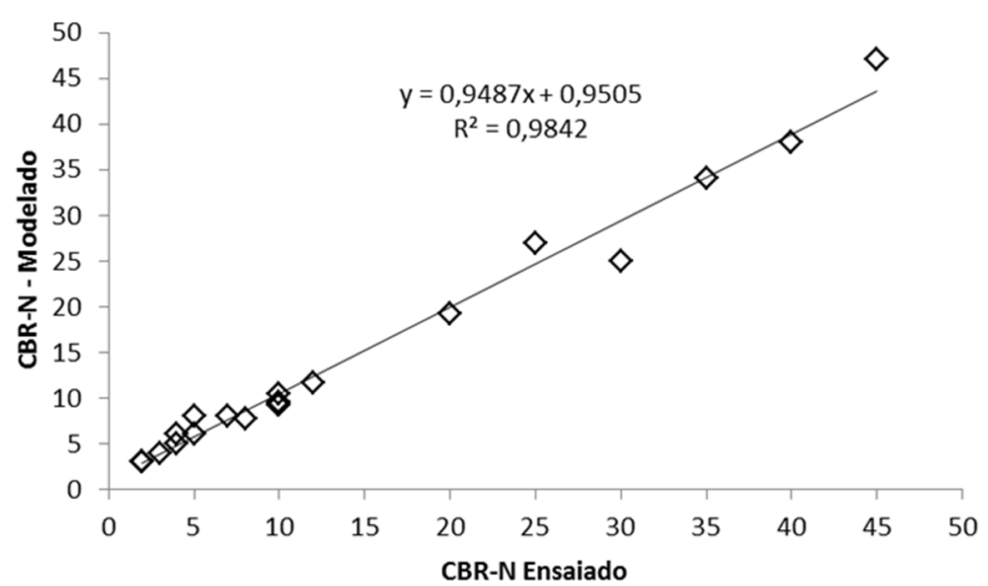

Figura 14. Correlação entre dados ensaiados e dados estimados de CBR-N

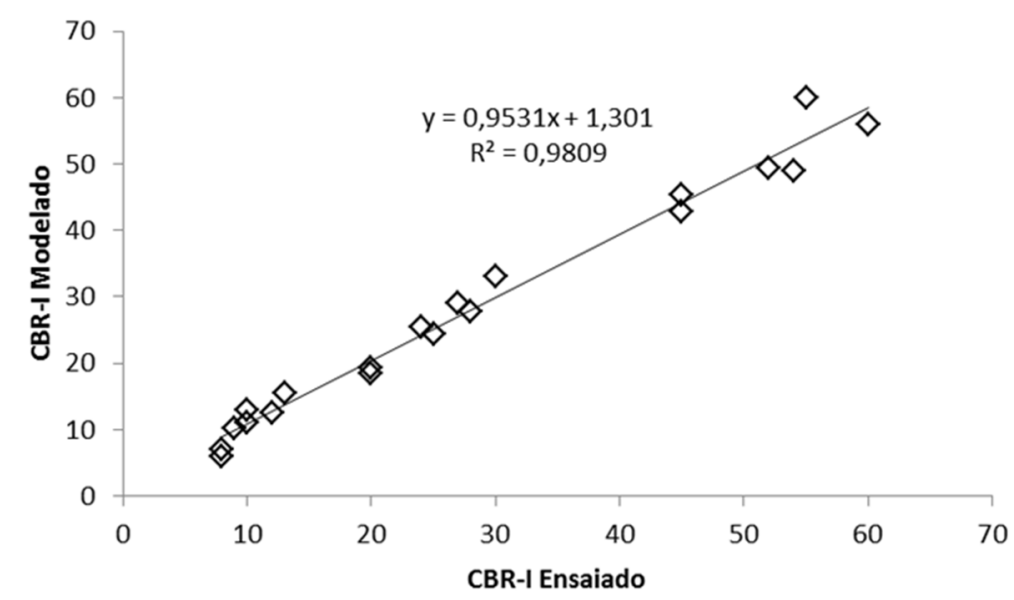

Figura 15. Correlação entre dados ensaiados e dados estimados de CBR-I 
De posse dos coeficientes de ajuste das Figuras 12 e 13, é possível afirmar que os dois modelos têm um bom desempenho quanto à previsão dos valores de CBR. Assim, os mapas podem ser utilizados para auxiliar na elaboração de pré-projetos ou estudo de viabilidade de dimensionamento empírico de pavimentos. Os coeficientes $\left(\mathrm{R}^{2}\right)$ dos modelos demonstram a capacidade que as RNA têm de prever características geotécnicas dos solos, sendo considerada uma ferramenta promissora para o problema em questão.

A partir dos resultados obtidos neste processo de modelagem é possível realizar comparações com outros modelos de previsão de características de solos de interesse em engenharia civil.

Gunaydin et al. (2010) previram resultados de Resistência à Compressão Simples a partir de propriedades físicas do próprio solo, como granulometria e índices físicos, utilizando Regressão Estatística e RNA, onde conseguiram resultados da ordem de $71 \%$ a $95 \%$ de acertos para diferentes amostras. Kuo et al. (2009) modelaram a capacidade de carga para fundações do tipo sapata em solos coesivos utilizando RNA e obtiveram acertos da ordem de $84 \%$ a $96 \%$. Juang et al. (2002) realizaram a modelagem do Overconsolidation Ratio Determination (OCR) a partir de dados de Cone Penetration Test (CPT) em areias, obtendo acertos da ordem de $84 \%$ utilizando técnicas de redes neurais artificiais. Taskiran (2010) realizou modelagem de CBR utilizando RNA e como dados de entrada granulometria e limites de consistência, onde obteve acertos variando de $61 \%$ a $91 \%$.

Com esses resultados reportados nos trabalhos descritos no parágrafo anterior, é possível afirmar que os resultados ilustrados nesta seção, obtidos a partir dos dois modelos gerados, são relevantes, dada a escala dos dados biofísicos disponíveis para a modelagem geotécnica neural.

\section{CONCLUSÃO}

Para o conjunto atual de dados disponível, a precisão dos modelos foi em torno de 0,98 . Não se conseguiu obter valores maiores, provavelmente pelo fato dos dados serem oriundos de diferentes fontes, podendo ter havido alguma inconsistência amostral, mesmo com a realização de filtros de dados. No entanto, acredita-se que este trabalho contribuiu para a identificação e mapeamento de solos da RMF com fins de pavimentação, a partir de uma metodologia de baixo custo, uma vez que usou em sua totalidade dados secundários.

Observou-se que é possível obter as informações geotécnicas mecânicas de CBR-N e CBR-I, como dados de saída de modelos neurais a partir de dados geotécnicos secundários e características biofísicas (Geologia, Pedologia, Vegetação, Geomorfologia, Altimetria, Coordenadas Este e Norte) como dados de entrada. Ressalta-se que as características biofísicas estão presentes em bases cartográficas disponibilizadas pelos órgãos do governo que detém tais informações.

Acredita-se que essa metodologia pode ser replicada para todas as regiões do Brasil, pois existem informações geotécnicas disponíveis em todos os órgãos rodoviários do País, bem como variáveis biofísicas, podendo ainda ser testadas outras variáveis para melhorar os ajustes dos modelos, como por exemplo: declividade, umidade, índice de radiação solar, iluminação, dentre outras variáveis espaciais que podem ser obtidas através de (MDT) modelos digitais do terreno com aplicação de análise espacial. Por fim, essa metodologia pode auxiliar na facilitação do reconhecimento prévio dos solos para finalidades de pavimentação no estado do Ceará e no Brasil, de maneira a propiciar uma maior economia na fase de anteprojeto e planejamento de construção e conservação de rodovias. Dessa forma, os recursos públicos serão poupados, podendo ser destinados a outros programas e setores mais carentes da sociedade.

\section{REFERÊNCIAS}

ALMEIDA, Márcio. S. S.; MARQUES, Maria. Esther. S.; MIRANDA, Talita Caroline . Lowland Reclamation in Urban Areas. In: Geotechnical Infrastructure for Mega Cities and New Capitals, 2008, Búzios. XIV COBRAMSEG, 2008.

BEALE, M. H.; HAGAN, M. T., DEMUTH H. B (2010), Neural Network Toolbox ${ }^{\mathrm{TM}} 7$ - User's Guide.

BOCKHEIM, J.G., GENNADIYEV, A.N., HAMMER R.D., TANDARICH J.P., (2005). The Historical development of key concepts in Pedology. Geoderma 124, 23-36. 
DOI:10.1016/j.geoderma.2004.03.004

BUI, D., TIEN, H., TIEN, C.; REVHAUG, I.; PRADHAN, B..; NGUYEN, D. B. “Landslide susceptibility mapping along the national road 32 of Vietnam using GIS-based j48 decision tree classifier and its ensembles." Cartography from pole to pole, pag. 303-317. Editora Springer Berlin Heidelberg, 2014. DOI:10.1007/978-3-642-32618-9_22

CÂMARA, G.; MEDEIROS, C. B.; CASA NOVA, M. A.; HEMERLY, A.; MAGALHÃES, G. (2004) Anatomia de sistemas de informação geográfica. Escola de Computação, SBC.

CÂMARA, A. S. (1996). Spatial Simulation Modelling. Spatial Analytical Perspectives on GIS. M. Fisher. London, Taylor \& Francis: 213-218.

CATEN, A. ten; DALMOLIN, R.S.D.; PEDRON, F. de A.; MENDONCA-SANTOS, M. de L. Regressões logísticas múltiplas: fatores que influenciam sua aplicação na predição de classes de solos. Revista Brasileira de Ciência do Solo, v.35, p.53-62, 2011b. DOI:10.1590/S0100-06832011000100005.

DEBELLA-GILO M.; ETZELMÜLLER B., (2009), Spatial prediction of soil classes using digital terrain analysis and multinomial logistic regression modeling integrated in GIS: Examples from Vestfold County, Norway, Catena, v. 77, p. 8-18, 2009. DOI:10.1016/j.catena.2008.12.001

DNIT (2006), Manual De Pavimentação, 2006.

FRANCO, F.A.C.P., Método de Dimensionamento Mecanístico-Empírico de Pavimentos Asfálticos - SISPAV, 2007, 294p. Tese (Doutorado em ciências em engenharia civil) - Universidade Federal do Rio de Janeiro, Rio de Janeiro.

FRITZEN, M. A., Desenvolvimento e Validação de Função de Transferência para Previsão do Dano por Fadiga em Pavimentos Asfálticos / Marcos Antonio Fritzen - Rio de Janeiro: UFRJ/COPPE, 2016.

GUILHERME, A. T. P.; RIBEIRO, A. J. A. ; CABRAL, W. S. ; SILVA, C. A. U. ; BARROSO, S. H. A. ; CASTRO, I. W. . Um Método para Construção de um Banco de Dados com fins de Modelagem Geotécnica para Pavimentação dos Solos da Microrregião de Mossoró-RN. In: XXX Congresso Nacional de Pesquisa em Transporte da ANPET, 2016, Rio de Janeiro. Anais, 2016. p. 8596.

GUNAYDIN O., GOKOGLU A.; FENER M., (2010), Prediction of artificial soil's unconfined compression strength test using statistical analyses and artificial neural networks, Advances in Engineering Software, v. 41, p. 1115-1123, 2010. DOI:10.1016/j.advengsoft.2010.06.008

HARTEMINK, A.E., MCBRATNEY, A.B. A soil science renaissance. Geoderma, 148:123-129, 2008. DOI:10.1016/j.geoderma.2008.10.006

HAYKIN (2001) Neural Networks, A Comprehensive Foundation. Second Edition, Pearson Education, McMaster University, Hamilton, Ontario, Canada.

JOHARI A.; JAVADI A. A.; HABIBAGAHI G., (2011), Modelling the mechanical behaviour of unsaturated soils using a genetic algorithm-based neural network, Computers and Geotechnics, v 38, p. 2-13, 2011. DOI:10.1016/j.compgeo.2010.08.011

JUANG, C. H., LU, P. C., CHEN, C. J. (2002), Predicting Geotechnical Parameters of Sands from CPT Measurements Using Neural Networks. Computer-Aided Civil and Infrastructure Engineering 17 (2002) 31-42.

DOI:10.1111/1467-8667.00250

KEMPEN B.; BRUS D. J., HEUVELINK G. B.M., STOORVOGEL J. J., (2009), Updating the 1:50,000 Dutch soil map using legacy soil data: A multinomial logistic regression approach. Geoderma, Amsterdam, v 151, p. 311-326, 2009. DOI:10.1016/j.geoderma.2009.04.023

LAGACHERIE, P., MCBRATNEY, A.B. Spatial soil information systems and spatial soil inference systems: Perspectives for digital soil mapping. Digital soil mapping: An introductory perspective. Amsterdam, Elsevier, 2007. p.3-22.

MCBRATNEY, A. B.; MENDONCA SANTOS, M. L.; MINASNY, B., (2003), On digital soil mapping. Geoderma, Amsterdam, v. 117, n. 1-2, p. 3-52, 2003. DOI:10.1016/S0016-7061(03)00223-4

MCCULLOCH, W. S. AND W. H. PITTS: 1943, 'A Logical Calculus of the Ideas Immanent in Nervous Activity', Bulletin of Mathematical Biophysics 7, 115-133. Reprinted in McCulloch 1964, pp. 16-39.

OH, T. C., PRADHAN, B. Application of a neuro-fuzzy model to landslide-susceptibility mapping for shallow landslides in a tropical hilly area. Computers \& Geosciences 37 (9), pag. 1264 - 1276, 2011. DOI:10.1016/j.cageo.2010.10.012

RIBEIRO, A. J. A.; DA SILVA, C. A. U.;BARROSO, S. H. A (2015). Neural Estimation of Localization and Classification of Soils for Use in Low-Traffic-Volume Roads. Transportation Research Record, v. 2473, p. 98-106, 2015. DOI:10.3141/2473-12

RIBEIRO, ANTONIO JÚNIOR ALVES; UCHÔA DA SILVA, CARLOS AUGUSTO ; DE ARAÚJO BARROSO, SUELLY HELENA . Metodologia Para Criação De Um Banco De Dados Georeferenciado a Partir de Dados Geotécnicos Obtidos Em -As Built- e Projetos Rodoviários. REEC - Revista Eletrônica de Engenharia Civil, v. 12, p. 1-13, 2016. DOI:10.5216/reec.v12i2.39413

RIBEIRO, A. J. A., ROSA, M. E. R., REIS, G. A., Comparação entre Diferentes Bases Altimétricas para Delimitação de Bacias e Extração de Drenagens. Revista Eletrônica de Gestão e Tecnologias Ambientais, v. 4, p. 193, 2016. DOI: 10.9771/gesta.v4i2.14992

ROSENBLATT, FRANK. 1958. The perceptron: A probabilistic model for information storage and organization in the brain. Psychological Review 6: 386-408.

SCULL, P., FRANKLIN, J., CHADWICK, O.A., MCARTHUR, D. (2003), Predictive soil mapping a review. Progress in Physical Geography, v. 27, p. 171-197, 2003.

SOUZA, M. L. (1979), Método de projeto de pavimentos flexíveis. 2. ed. Rio de Janeiro: DNER, 1979.

TASKIRAN, T. (2010), Prediction of California bearing ratio (CBR) of fine grained soils by AI methods. Advances in Engineering Software 41 (2010) 886-892. DOI:10.1016/j.advengsoft.2010.01.003 
YILDIRIM, B., GUNAYDIN. O., (2011), Estimation of California bearing ratio by using soft computing systems. Expert Systems with Applications 38 (2011) 6381-6391. DOI:10.1016/j.eswa.2010.12.054

ZEGHAL, M., KHOGALI, W., (2005), Predicting the resilient modulus of unbound granular materials by neural networks. National Research Council Canada (NRCC-47704). BCRA 2005, Trondheim, Norway, June 27-29, 2005, pp. 1-9.

Anderson, D.A. e R. Dongre (1995) The SHRP Direct Tension Specification Test - Its Development and Use. Physical Properties of Asphalt Cement Binders, J.C. Hardin, Ed. ASTM Special Technical Publication 1241. American Society for Testing and Materials, Philadelphia, PA, p. 51-66. 